\title{
Methotrexate and maintenance of remission in Crohn's disease
}

\author{
Martin Fishman MD FRCP
}

\begin{abstract}
ARTICLE
Feagan BG, Fedorak RN, Irvine FJ, et al. A comparison of methotrexate with placebo for the maintenance of remission in Crohn's disease. North American Crohn's Study Group Investigators. New England Journal of Medicine 2000;342(22):1627-32.
\end{abstract}

\section{ARTICLE SUMMARY}

This randomized, double-blind, placebo controlled, prospective multicentre trial studied the efficacy of methotrexate (MTX) in maintaining remission of Crohn's disease (CD). Seventy-six patients with CD, in whom remission had been induced by MTX $25 \mathrm{mg}$ given intramuscularly weekly for 16 to 24 weeks, were randomly assigned to receive either MTX $15 \mathrm{mg}$ intramuscularly weekly or placebo for 40 weeks. Remission was maintained in $65 \%$ of the treatment group and $39 \%$ of the placebo group ( $\mathrm{P}=0.04)$. Adverse events were infrequent and minor in both groups.

\section{COMMENTARY}

Therapeutic trials for CD are often based on an agent's record in treating rheumatoid arthritis. This is the case with MTX as it was with sulphasalazine, corticosteroids, purine antimetabolites and infliximab. Gastroenterologists seem to follow the lead of their rheumatology colleagues, not only in initiating clinical studies, but also in using new agents in clinical practice. We have taken longer to incorporate the purine antimetabolites into our daily routine and we have been especially hesitant to use MTX. At a recent weekly clinical gastroenterology rounds that I attended at a major teaching hospital, only one of six gastroenterologists present had experience with MTX in treating CD and that was in only one patient. Is this about to change?

MTX may finally be coming of age, thanks largely to the collaborative effort of the Canadians who comprise the majority of the North American Crohn's Study Group Investigators. Their first seminal publication studied MTX in the induction of remission of active Crohn's disease (1). This trial confirmed the findings of smaller, uncontrolled studies $(2,3)$ and set the stage for subsequent publications, which further substantiated the role of MTX in inducing remission (4-8). The more recent maintenance trial again sets the benchmark.

The results are compelling, despite the somewhat limited study power resulting from a modest sample size. The superiority of MTX to placebo was both statistically and clinically significant. MTX was also well tolerated. However, subjects had been preselected based on their initial response to and tolerance of the drug. Patients with liver or lung disease, diabetes mellitus and obesity were excluded. Potential participants who drink more than seven alcoholic beverages/week or who could not take effective contraceptive measures were not allowed to participate. Nonetheless, for patients whose CD is initially controlled by MTX, it is worth continuing the medication for at least 40 weeks based on this study.

Determining the appropriate role for MTX in maintenance therapy will require further study. For example, the role of MTX in maintaining remission induced by other agents, such as corticosteroids or infliximab, remains to be established. This is a potentially important area, especially for patients who are unresponsive to or intolerant of purine antimetabolites, or who become unable to continue infliximab therapy. In the meantime, it will be interesting to see how many gastroenterologists will develop experience and comfort with MTX.

\section{REFERENCES}

1. Feagan BG, Rechon J, Fedorak RN, et al. Methotrexate for the treatment of Crohn's disease. N Engl J Med 1995;332:292-7.

2. Kozarek RA, Patterson DJ, Gelfand MD, et al. Methotrexate induces clinical and histologic remission in patients with refractory inflammatory bowel disease. Ann Intern Med 1989;110:333-6.

3. Baron TH, Truss CD, Elson CO. Low-dose oral methotrexate in refractory inflammatory bowel disease. Dig Dis Sci 1993;38:1851-6.

4. Lemann M, Chamiot-Prieur C, Mesnard B, et al. Methotrexate for the treatment of refractory Crohn's disease. Aliment Pharmacol Ther 1996;10:309-14

5. Oren R, Moshkowitz M, Odes S, et al. Methotrexate in chronic active Crohn's disease: A double-blind, randomized, Israeli multicentre trial. Am J Gastroenterol 1997;92:2203-9.

6. Lemann M, Zenjari T, Bouhnik Y, et al. Methotrexate in Crohn's disease: Long-term efficacy and toxicity. Am J Gastroenterol 2000;95:1730-4.

7. Mate-Jimenez J, Hermida C, Cantero-Perona J, et al. 6-mercaptopurine or methotrexate added to prednisone induces and maintains remission in steroid-dependent inflammatory bowel disease. Eur J Gastroenterol Hepatol 2000;12:1227-33.

8. Chong RY, Hanauer SB, Cohen RD. Efficacy of parenteral methotrexate in refractory Crohn's disease. Aliment Pharmacol Ther 2000;15:35-44. 


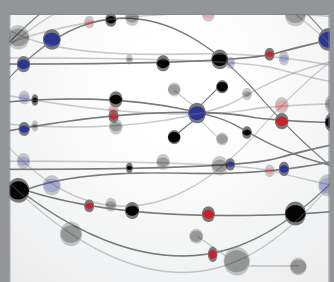

The Scientific World Journal
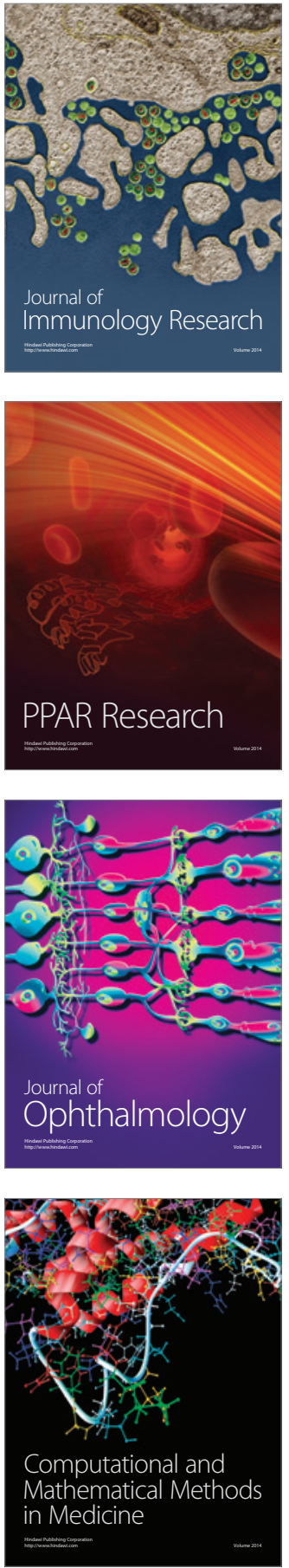

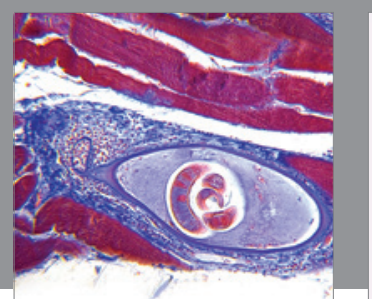

Gastroenterology Research and Practice

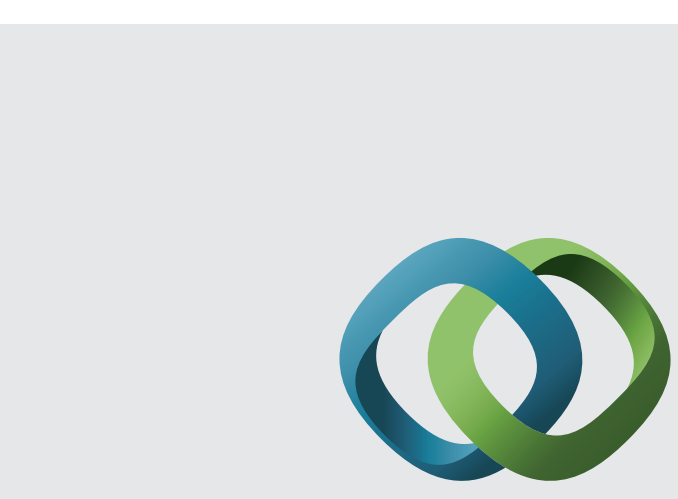

\section{Hindawi}

Submit your manuscripts at

http://www.hindawi.com
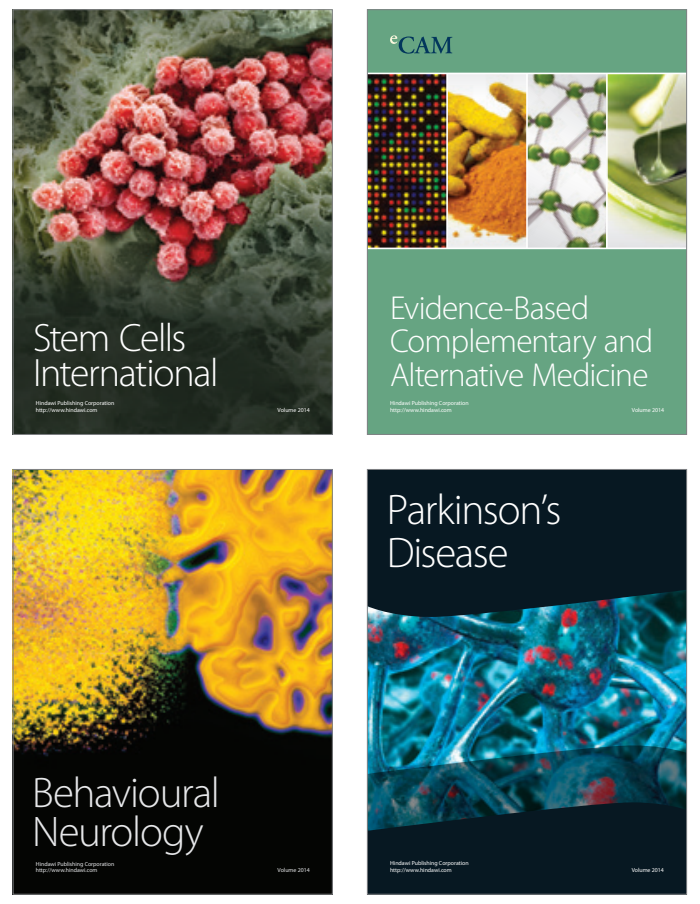
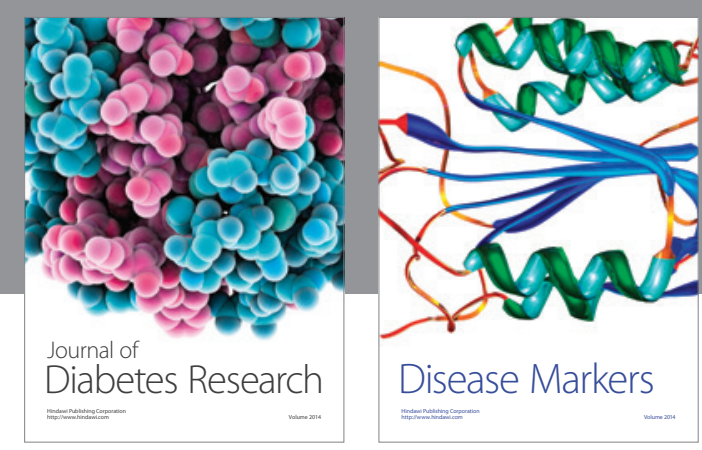

Disease Markers
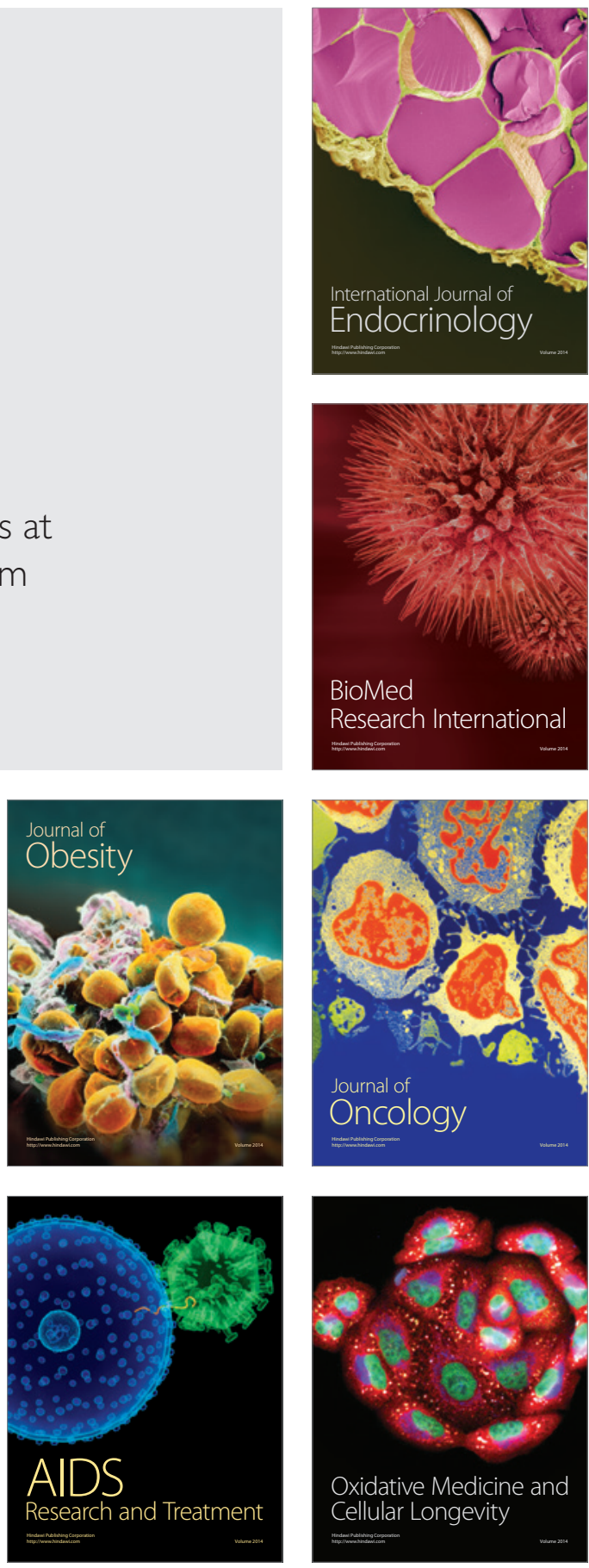